\title{
PENGARUH PENERAPAN MODEL PEMBELAJARAN KOOPERATIF TIPE STAD TERHADAP HASIL BELAJAR BOLA BASKET PADA SISWA KELAS VII SMP NEGERI 6 SINGARAJA
}

\author{
I Wayan Ardha Wira Parwata, Nyoman Kanca, Adnyana Putra
}

\author{
Jurusan Pendidikan Jasmani Kesehatan dan Rekreasi \\ Fakultas Olahraga dan Kesehatan Universitas Pendidikan Ganesha, \\ Kampus Tengah Undiksha Singaraja, Jalan Udayana Singaraja-Bali Tlp. (0362) 32559 \\ e-mail: \{ardhaparwata@gmail.com,nyoman.kanca@undiksha.ac.id, \\ adnyanaputra@undiksha.ac.id\}
}

\begin{abstract}
Abstrak
Penelitian ini bertujuan untuk mengetahui pengaruh penerapan model pembelajaran kooperatif tipe student team achievement division (STAD) terhadap hasil belajar teknik dasar passing (chest pass dan bounce pass) bola basket. Jenis penelitian adalah eksperimen sungguhan dengan rancangan the randomized pretest-posttest control group the same subjec design. Populasi adalah seluruh siswa kelas VII SMP Negeri 6 Singaraja tahun pelajaran 2016/2017, keseluruhan jumlah populasi 334 orang. Pengambilan sampel yang digunakan simple random sampling berdasarkan kelas. Kelas yang menjadi sampel penelitian adalah kelas VII A1 sebagai kelompok eksperimen dan VII A2 sebagai kelompok kontrol. Eksperimen dilakukan sebanyak 3 kali perlakuan diluar pretes-posttest. Data hasil belajar dikumpulkan melalui tes essay, observasi dan unjuk kerja. Analisis data menggunakan uji-t dengan bantuan SPSS 16.0 for Windows. Rata-rata kelompok eksperimen adalah 87.622 lebih tinggi dari rata-rata kelompok kontrol adalah 82.567. Signifikansi pada tes normalitas adalah 0.71 (kelompok eksperimen) dan 0.52 (kelompok kontrol). Signifikansi pada tes homogenitas adalah 0.772. Signifikansi pada uji hipotesis diperoleh melalui uji parametrik (uji Independent Samples Test) adalah 0.009. Disimpulkan bahwa penerapan model pembelajaran kooperatif tipe STAD berpengaruh signifikan terhadap hasil belajar teknik dasar passing (chest pass dan bounce pass)bola basket. Disarankan kepada guru penjasorkes dapat menerapkan model pembelajaran kooperatif tipe STAD karena terbukti berpengaruh signifikan terhadap peningkatan hasil belajar siswa.
\end{abstract}

Kata-kata kunci: Model pembelajaran kooperatif tipe STAD, hasil belajar, bola basket

\begin{abstract}
This research aimed to determine the effect of implementing cooperative learning model student team achievement division (STAD) to the learning outcomes of basic techniques of passing (chest pass and bounce pass) basketball. This research was a true-experimental researching the randomized pretest-posttest control group the same subject design. The population was students of class VII SMP Negeri 6 Singaraja academic year 2016/2017, with the population of the research was 334 people. Sampling technique used was simple random sampling based on class. The class into the sample was class VII A1 as control group and VII A2 as experimental group. The experimental was conducted three times treatment outside of pretest-posttest. Data were collected through essay tests, observation and performance tests. Data analysis using t-test with SPSS 16.0 for Windows. Average on experimental group was 87.622 higher than average control was 82.567. Significance on tests of normality was 0.71 (experimental group) and 0.52 (control group). Significance on tests of homogenity was 0.772 . Significance on tests of hypotheses obtained through parametric test (independent Samples Test) was 0.009.Based on the above exposure, implementation of learning model cooperative type STAD effect significantly to the result of learning basic techniques passing basketball. It is recommended to the penjasorkes teacher can implement cooperative learning model type STAD because proven effect significantly to the improvement of student's learning outcome.
\end{abstract}

Key words: Cooperative learning model type STAD, learning outcome, basketball. 


\section{PENDAHULUAN}

Proses pembelajaran merupakan inti dari kegiatan pendidikan di sekolah khususnya dalam pembelajaran Pendidikan Jasmani Olahraga dan Kesehatan (Penjasorkes). Pembelajaran merupakan suatu proses yang melibatkan interaksi antara siswa, guru, fasilitas dan lingkungan untuk memperoleh pengetahuan, keterampilan atau sikap yang baru dalam mencapai tujuan yang dirumuskan. Pembelajaran penjasorkes bertujuan untuk membantu siswa dalam usaha meningkatkan derajat kesehatan dan kebugaran jasmani melalui keterampilan gerak dasar dalam berbagai aktivitas jasmani. Dengan demikian dalam kegiatan sehari-harinya guru penjasorkes selalu bersentuhan dengan aktivitas gerak fisik. Aktivitas fisik tersebut akan tampak dalam aktivitas gerak siswa saat melakukan tugas-tugas gerak dalam proses pembelajaran.

Dari konsep-konsep pembelajaran penjasorkes di atas, guru harus selalu mampu mempersiapkan diri untuk melaksanakan proses pembelajaran dengan baik dan benar. Peranan guru dalam proses pembelajaran Penjasorkes sangat menentukan keberhasilan proses pembelajaran. Guru sebagai pengelola proses pembelajaran diharapkan mampu menyediakan lingkungan belajar yang kondusif sehingga siswa dapat belajar dengan baik. Dalam pelaksanaannya seorang guru penjasorkes diharapkan untuk bisa mengajarkan berbagai keterampilan gerak dasar, teknik dan strategi permainan dalam olahraga, internalisasi nilai-nilai dan pembiasaan pola hidup sehat. Untuk itu, maka sangatlah penting bagi para guru memahami karakteristik materi, peserta didik dan metodologi pembelajaran dalam proses pembelajaran terutama yang berkaitan dengan pemilihan model-model pembelajaran inovatif.
Berdasarkan hasil ulangan harian di SMP Negeri 6 Singaraja tahun pelajaran 2016/2017 pada hari Selasa, 11 Oktober 2016 khususnya pada mata pelajaran penjasorkes. Hasil belajar teknik dasar passing bola basket pada siswa kelas VII A1 yang terdiri dari 27 orang siswa yaitu tidak ada siswa memperoleh nilai $\leq 54$, tidak ada siswa memperoleh nilai $55-64,23$ orang siswa memperoleh nilai $65-74,4$ orang siswa memperoleh nilai 75-85 dan tidak ada siswa memperoleh nilai $\geq 86$. Sedangkan pada kelas VII A2 yang terdiri dari tidak ada siswa memperoleh nilai $\leq 54$, tidak ada siswa memperoleh nilai 55-64, 25 orang siswa memperoleh nilai $65-74,2$ orang siswa memperoleh nilai $75-85$, dan tidak ada siswa memperoleh nilai $\geq 86$. Kriteria Ketuntasan Minimal (KKM) yang berlaku di kelas VII SMP Negeri 6 Singaraja khususnya pada mata pelajaran penjasorkes adalah 75. Dengan hasil ini, maka bisa diketahui dari KKM hasil belajar passing bola basket, hanya terdapat 4 orang siswa di kelas VII A1 dan 2 orang siswa di kelas VII A2 yang tuntas dan memenuhi KKM, sedangkan siswa yang tidak tuntas dan belum memenuhi KKM adalah 23 orang siswa di kelas VII A1 dan 25 orang siswa di kelas VII A2.

Melihat hasil belajar siswa masih rendah seperti tersebut di atas, maka peneliti mencari akar penyebabnya dengan menganalisis beberapa faktor. Pokok permasalahan yang ditemukan peneliti dari hasil ulangan harian di SMP Negeri 6 Singaraja pada hari Selasa tanggal 11 Oktober 2016 ada beberapa penyebab permasalahan pada hasil belajar siswa yang dicapai oleh siswa yaitu: 1) model pembelajaran yang kurang inovatif dan kreatif, karena guru masih menggunakan model pembelajaran konvensional yang sifatnya monoton dengan metode ceramah dari guru; 2) Kurangnya kesempatan berinteraksi 
antara guru dengan siswa, dan siswa dengan siswa, karena proses pembelajaran masih satu arah lebih didominasi oleh guru; 3) Guru jarang mengajak siswa untuk belajar secara berkelompok dan jarang memberikan diskusi kepada siswa pada saat proses pembelajaran, karena guru cenderung dominan menggunakan metode ceramah dan kurangnya wawasan guru tentang tehnik dan strategi pembelajaran yang menyenangkan. Hal ini menyebabkan siswa kurang mendapatkan pengalaman belajar dari temannya ataupun guru yang sangat mempengaruhi hasil belajar.

Berdasarkan

masalah

sebagaimana yang telah dideskripsikan di atas, maka dalam mengatasi permasalahan yang dihadapi khususnya masalah pembelajaran penjasorkes di kelas VII SMP Negeri 6 Singaraja perlu dicarikan alternatif pemecahan masalah yang akan dilakukan adalah dengan melakukan inovasi model pembelajaran yang inovatif yang mampu meningkatkan hasil belajar siswa. Untuk itu dapat dilakukan dengan merancang proses pembelajaran yang inovatif bagi siswa. Siswa yang proses belajarnya masih kurang dikarenakan guru yang kurang inovatif memilih model pembelajaran sehingga disarankan untuk memilih model pembelajaran yang efektif seperti model pembelajaran kooperatif tipe Student Team Achievement Division (STAD).

Model pembelajaran kooperatif tipe STAD sangat cocok diterapkan di SMP Negeri 6 Singaraja karena model pembelajaran ini sesuai dengan karakteristik siswa di SMP Negeri 6 Singaraja. Menurut Trianto (2007:52) model pembelajaran kooperatif tipe STAD merupakan salah satu tipe dari model pembelajaran kooperatif dengan menggunakan kelompok-kelompok kecil dengan jumlah anggota tiap kelompok 45 orang siswa secara heterogen. Diawali dengan penyampaian tujuan pembelajaran, penyampaian materi, kegiatan kelompok, kuis, dan penghargaan kelompok.

Dalam penelitian ini peneliti ingin mengangkat model pembelajaran kooperatif tipe STAD. Pembelajaran dengan menggunakan model pembelajaran kooperatif tipe STAD memungkinkan membantu kesulitan guru dalam memberikan materi pembelajaran kepada siswa dan pembelajaran di kelas menjadi lebih efektif sehingga dapat meningkatkan hasil belajar siswa. Menggunakan model pembelajaran kooperatif tipe STAD akan mendorong siswa untuk aktif bertukar pikiran dengan temannya dalam memahami suatu materi pembelajaran pendidikan jasmani olahraga dan kesehatan di kelas maupun di kehidupan sehari-hari.

Selain itu, pemilihan tentang model pembelajaran STAD ini juga dikuatkan oleh hasil penelitian dari peneliti-peneliti sebelumnya, antara lain: (1) Sudiarpa (2015) menyatakan bahwa hasil penelitian menunjukan bahwa secara keseluruhan rata-rata skor hasil belajar IPA siswa pada kelompok eksperimen yaitu sebesar 13,69 lebih tinggi dibandingkan dengan rata-rata skor hasil belajar siswa pada kelompok kontrol yaitu 11,73 . Dengan demikian nilai rata-rata kelompok eksperimen lebih dari pada nilai rata-rata kelompok kontrol. (2) Sariyasa (2013) menunjukkan bahwa hasil belajar siswa yang mengikuti pembelajaran dengan model pembelajaran kooperatif tipe STAD lebih baik daripada siswa yang mengikuti model pembelajaran konvensional, keterampilan sosial pada siswa yang mengikuti pembelajaran dengan model pembelajaran kooperatif tipe STAD lebih baik daripada siswa yang mengikuti model pembelajaran konvensional, dan hasil belajar dan keterampilan sosial siswa yang mengikuti model pembelajaran 
kooperatif tipe STAD lebih baik daripada model pembelajaran konvensional. (3) Faridha (2013) menemukan bahwa terdapat perbedaan hasil belajar kimia antara peserta didik yang diajar dengan model pembelajaran kooperatif tipe STAD dengan peserta didik yang diajar dengan menggunakan model pembelajaran kooperatif tipe TGT pada materi pokok ikatan kimia. (4) Puspawati (2013) menemukan bahwa prestasi belajar IPS dengan model pembelajaran kooperatif tipe STAD lebih baik daripada model pembelajaran konvensional. (5) Marsi (2014) menemukan bahwa terdapat perbedaan prestasi belajar matematika yang signifikan antara siswa yang belajar menggunakan pembelajaran kooperatif tipe STAD dan pembelajaran konvensional.

Dari uraian di atas maka timbul keinginan untuk meneliti permasalahan tersebut yang kemudian dirangkai dalam sebuah judul "Pengaruh Penerapan Model Pembelajaran Kooperatif Tipe STAD Terhadap Hasil Belajar Passing Basket

Tabel 01.

Descriptive Statistics

\begin{tabular}{ccccccc}
\hline Pretest & $\mathrm{n}$ & Minimum & Maximum & Sum & Mean & $\begin{array}{c}\text { Std. } \\
\text { Deviation } \\
8.2351\end{array}$ \\
\hline kelas eksperimen & 27 & 61.6 & 85.0 & 1967.2 & 72.859 & 8.035 \\
\hline kelas control & 27 & 61.6 & 85.0 & 1987.6 & 73.615 & 8.0395
\end{tabular}

Pada Siswa Kelas VII SMP Negeri 6 Singaraja Tahun Pelajaran 2016/2017".

\section{HASIL dan PEMBAHASAN}

\section{METODE PENELITIAN}

Jenis penelitian yang digunakan dalam penelitian ini adalah eksperimen sesungguhnya (true experimental). Rancangan penelitian yang digunakan adalah rancangan the randomized pretestposttest control group the same subjec design (Kanca, 2010:86).

Dalam penelitian ini, populasi yang digunakan adalah keseluruhan kelas VII SMP Negeri 6 Singaraja tahun pelajaran
2016/2017. Banyak siswa seluruhnya 334 orang yang tersebar dalam 12 kelas yaitu kelas VII A1, VII A2, VII B1, VII B2, VII B3, VII B4, VII B5, VII B6, VII B8, VII B9, VII B10. Pengambilan sampel dengan teknik simple random sampling berdasarkan kelas sehingga terdistribusi ke dalam 2 kelas yaitu: VII A1 berjumlah 27 orang sebagai kelas eksperimen dan VII A2 berjumlah 27 orang sebagai kelas kontrol. Pengambilan data hasil belajar dilakukan dengan cara memberikan tes essay, observasi, dan unjuk kerja. Analisis data dilakukan dengan menggunakan Uji-t dengan bantuan software SPSS 16.00 for Windows. Sebelum dilakukan uji-t terlebih dahulu data diuji normalitas dan homogenitasnya. 
Tabel 02.

Descriptive Statistics

\begin{tabular}{cccccccc}
\hline Posttest & $\mathrm{n}$ & Minimum & Maximum & Sum & Mean & $\begin{array}{c}\text { Std. } \\
\text { Deviation }\end{array}$ \\
\cline { 1 - 5 } kelas eksperimen & 27 & 76.6 & 96.6 & 2365.8 & 87.622 & 6.9234 \\
\hline kelas kontrol & 27 & 71.6 & 93.3 & 2229.3 & 82.567 & 6.7068
\end{tabular}

Histogram Data Pretest Kelas Eksperimen

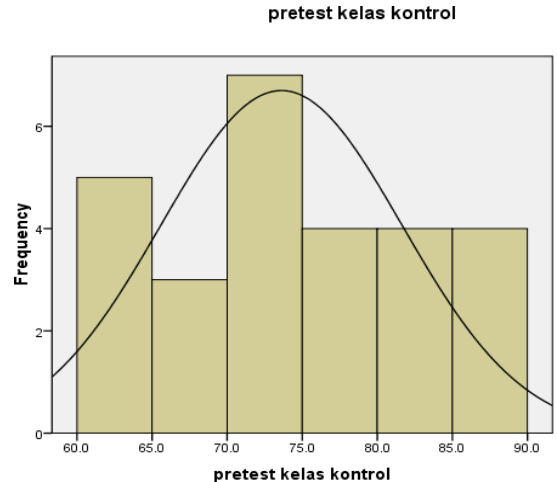

Gambar 02.

Histogram Data Pretest Kelas Kontrol

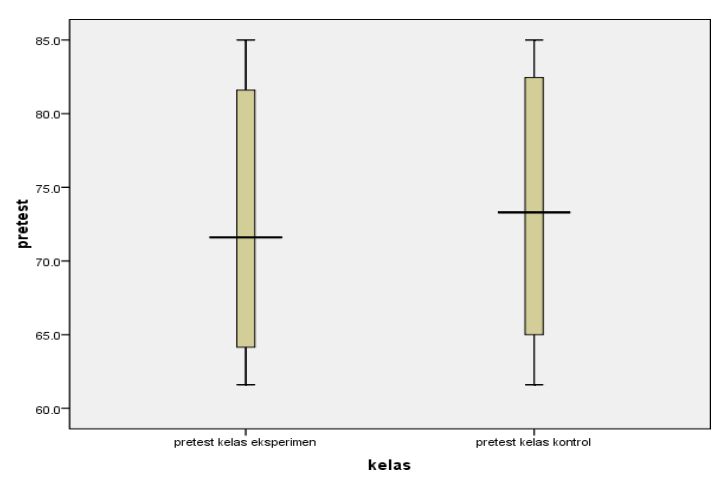

Gambar 03.

Frekuensi Variabel Pretest

Berdasarkan tabel 01, histogram, dan frekuensi variabel di atas data hasil pretest, standar deviasi kelas eksperimen $=8,2351$ sedangkan standar deviasi kelompok kontrol $=8,0395$. Rata-rata dari kelompok eksperimen $=72,859$ sedangkan rata-rata dari kelompok kontrol $=73,615$.

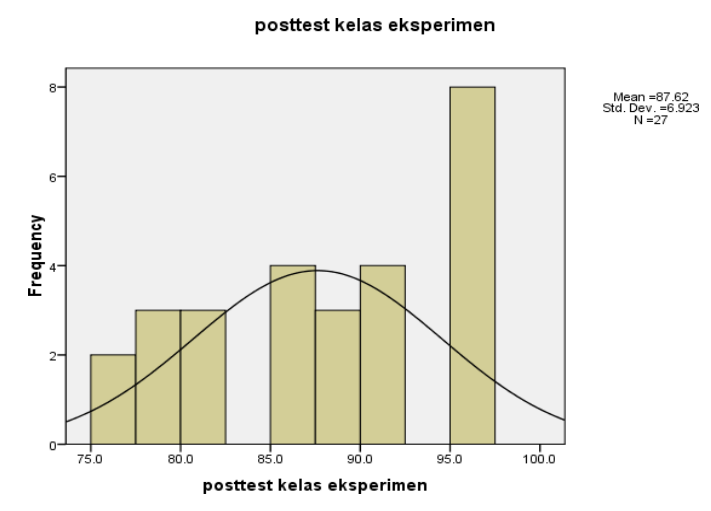

Gambar 04.

Histogram Data Posttest Kelas Eksperimen

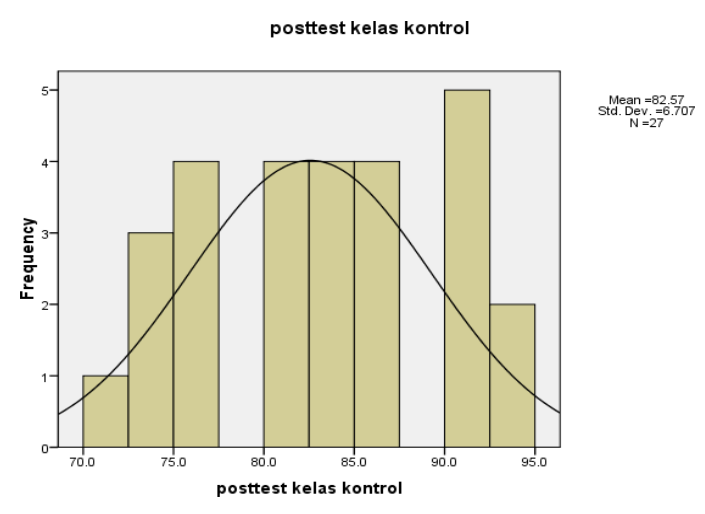

Gambar 05.

Histogram Data Posttest Kelas Kontrol

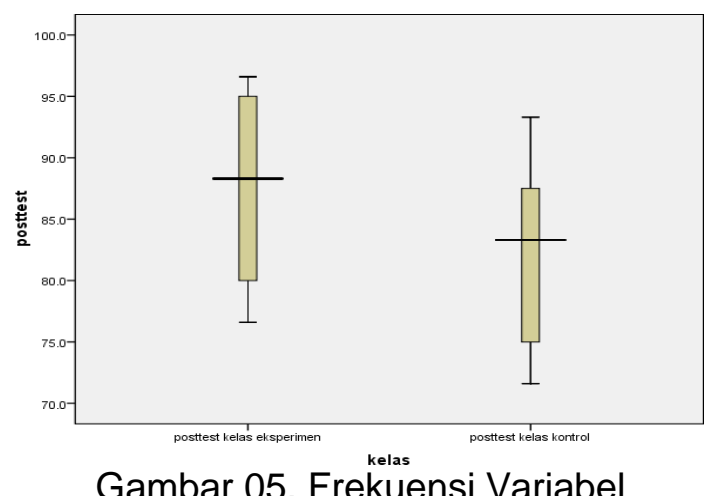

Posttest 
Berdasarkan tabel 02, histogram, dan frekuensi variabel di atas data hasil posttest, standar deviasi kelas eksperimen $=6,9234$ sedangkan standar deviasi kelas kontrol $=6,7068$. Rata-rata dari kelas eksperimen $=87,622$ sedangkan rata-rata dari kelas kontrol $=$ 82,567.Uji normalitas sebaran data digunakan rumus Kolmogorov-Smirnov pada signifikansi 0,05 . Uji normalitas pada pretest didapatkan hasil untuk nilai signifikansinya kelompok eksperimen $=$ 0.111 dan nilai signifikansinya kelompok kontrol adalah 0.098. Untuk semua variabel signifikansi pada uji KolmogorovSmirnov lebih besar dari 0,05 Dengan demikian maka semua sebaran data berdistribusi normal.

Berdasarkan hasil perhitungan homogenitas data menggunakan uji Levene's ditunjukkan bahwa untuk pretest teknik dasar passing bola basket pada kelas eksperimen dan kontrol dengan taraf signifikansi 0.872 maka $p$ lebih besar dari 0.05 . Dapat disimpulkan bahwa variansi pada setiap kelompok adalah sama (homogen).

Berdasarkan hasil pengujian uji-t pada pretest dengan menggunakan uji Independent Samples Test pada signifikansi 0.05 diperoleh nilai signifikansinya $=0.734$ maka $p>0.05$. Adapun keputusan yang diambil adalah terima $H_{0}$ dan tolak $H_{a}$. hasil ini menyatakan bahwa tidak ada perbedaan nilai pretest teknik dasar passing bola basket antara siswa yang dibelajarkan menggunakan model pembelajaran kooperatif tipe STAD dengan siswa yang dibelajarkan menggunakan model pembelajaran konvensional (ceramah, demonstrasi, dan penugasan). Oleh karena itu, uji beda dapat dilakukan pada data posttest.

Uji normalitas sebaran data digunakan rumus Kolmogorov-Smirnov pada signifikansi 0,05. Uji normalitas pada posttest didapatkan hasil untuk nilai signifikansinya kelompok eksperimen $=0.071$ dan nilai signifikansinya kelompok kontrol adalah 0.052. Untuk semua variabel signifikansi pada uji KolmogorovSmirnov lebih besar dari 0,05. Dengan demikian maka semua sebaran data berdistribusi normal.

Berdasarkan hasil perhitungan homogenitas data menggunakan uji Levene's ditunjukkan bahwa untuk posttest teknik dasar passing bola basket pada kelas eksperimen dan kontrol dengan taraf signifikansi 0,772 maka $p$ lebih besar dari 0.05. Dapat disimpulkan bahwa variansi pada setiap kelompok adalah sama (homogen).

Sedangkan pengujian uji hipotesis pada posttest dengan menggunakan uji Independent Samples Test pada signifikansi 0.05 diperoleh nilai signifikansinya $=0.009$. Adapun keputusan yang diambil adalah tolak $H_{0}$ dan terima $H_{a}$. hasil ini menyatakan bahwa terdapat perbedaan signifikan hasil belajar teknik dasar passing bola basket antara siswa yang dibelajarkan menggunakan model pembelajaran kooperatif tipe STAD dengan siswa yang dibelajarkan menggunakan model pembelajaran konvensional (ceramah, demonstrasi, dan penugasan). Oleh karena rata-rata pada kelompok eksperimen lebih tinggi disbanding kelompok kontrol maka dapat disimpulkan penerapan model pembelajaran kooperatif tipe STAD berpengaruh meningkat pada hasil belajar teknik dasar passing bola basket.

Hal ini sejalan dengan hasil penelitian sebelumnya yang dilakukan oleh Sudiarpa (2015) yang menemukan bahwa terdapat perbedaan hasil belajar IPA yang signifikan antara siswa yang mengikuti pembelajaran dengan model pembelajaran kooperatif STAD dengan siswa yang mengikuti pembelajaran dengan model pembelajaran konvensional dengan nilai $t_{\text {hitung }} 2,1024$ > $t_{\text {tabel }} 1,9913$. Selain itu penelitian yang dilakukan oleh Novia (2015) juga menemukan bahwa Hasil belajar PKn siswa yang mengikuti pembelajaran dengan menggunakan model 
pembelajaran kooperatif tipe STAD berbantuan multimedia pembelajaran lebih tinggi dibandingkan dengan siswa yang mengikuti pembelajaran konvensional, hal ini dapat dilihat dari nilai $t_{\text {hitung }}$ 6,045 lebih besar dari $t_{\text {tabel }}$ 2,000. Marliana (2015) terdapat perbedaan yang signifikan hasil belajar IPA antara siswa yang mengikuti pembelajaran dengan model pembelajaran STAD dan siswa yang mengikuti pembelajaran dengan model pembelajaran konvensional (thitung = $\left.11,499>t_{\text {tabel }}=1,665\right)$

\section{SIMPULAN dan SARAN}

Berdasarkan hasil pengujian hipotesis dan pembahasan, maka disimpulkan bahwa penerapan model pembelajaran kooperatif tipe STAD berpengaruh signifikan terhadap hasil belajar teknik dasar passing bola basket.Berdasarkan kesimpulan maka dapat diajukan beberapa saran untuk proses pembelajaran dan penelitian lebih lanjut sebagai berikut. 1) siswa, dengan diterapkannya model pembelajaran kooperatif tipe STAD diharapkan mampu meningkatkan hasil belajar teknik dasar passing bola basket siswa serta kualitas belajar. 2) guru di sekolah menengah pertama agar mengggunakan model pembelajaran kooperatif tipe STAD dalam melakukan pembelajaran di kelas agar siswa lebih termotivasi untuk belajar teknik dasar passing bola basket karena model ini menggunakan diskusi dan kuis- kuis. 3) sekolah, agar selalu berusaha meningkatkan kualitas pembelajaran di sekolah, salah satunya dengan cara mensosialisasikan penerapan suatu model pembelajaran yang inovatif, sehingga hasil belajar siswa meningkat. 4) peneliti lain yang berminat mengadakan penelitian lebih lanjut mengenai model pembelajaran kooperatif tipe STAD dapat menjadikan hasil penelitian ini sebagai salah satu referensi untuk meneliti dalam lingkup yang lebih luas, sehingga diperoleh sumbangan ilmu yang lebih baik dan sesuai dengan perkembanganzaman.

\section{DAFTAR PUSTAKA}

Ahriani, Faridha. (2013). Pengaruh model pembelajaran kooperatif dan gaya belajar terhadap hasil belajar kimia peserta didik kelas $X$ SMK

Negeri

2BantaengTersediapada:pasca.un diksha.ac.id/ejournal/index.php/jur nal pendas/article/view/768. (diaks es tanggal 3 Maret 2017).

Kanca, I Nyoman. 2010. Metode Penelitian Pengajaran Pendidikan Jasmani dan Olahraga. Singaraja :Universitas Pendidikan Ganesha

Marliana. (2015). Pengaruh Model Pembelajaran Kooperatif Tipe STAD Berbantuan Multimedia Pembelajaran Interaktif Terhadap Hasil Belajar IPA Tersedia pada: http://ejournal.undiksha.ac.id/inde $\underline{x}$ .php/JJTP/article/view/5607(diaks es tanggal 27 Februari 2017).

Marsi. Pengaruh Model Pembelajaran Kooperatif Tipe STAD dan Kemampuan Abstraksi terhadap Prestasi Belajar Matematika Siswa SMP Negeri 1 Bangli. Tersedia:http://pasca.undiksha.ac. i d/ejournal/index.php/jurnal_tp/artic I e/download/1086/834. (diakses tanggal 15 Juni 2017).

Novia. Pengaruh Model Pembelajaran Kooperatif Tipe STAD Berbantuan Multimedia Pembelajaran Terhadap Hasil Belajar PknTersedia

pada:

http://ejournal.undiksha.ac.id/inde x.php/JJTP/search/authors/view?

$\begin{array}{ll}\text { first } & \text { (diakses } \\ \text { tanggal } & 27 \text { Februari }\end{array}$
2017).

Puspawati. (2013). Pengaruh ModelPembelajaran Kooperatif Tipe STAD 


\begin{abstract}
Terhadap Minat
dan Prestasi Belajar IPS

Pada Siswa Kelas IV Sekolah

Dasar Nomor 3 Legian -

Badung. Tersedia pada:

http://pasca.undiksha.ac.id/ejourn

a

1/index.php/jurnal_pendas/article/

d ownload/506/298. (diakses

tanggal15 Juni 2017).
\end{abstract}

Sariyasa. (2013). Pengaruh

ModelPembelajaran

KooperatifSTAD Terhadap

Hasil Belajar IPS dan

Keterampilan Sosial pada Siswa

Kelas V SD Negeri 1 Joworawu

Lombok Timur Tahun Pelajaran

2012/2013 Tersedia

pada:

pasca.undiksha.ac.id/ejournal/ind

e

x.php/jurnal_pendas/article/view/

7 68.(diakses tanggal 27

Februari2017).

Sudiarpa, I Komang. (2015). Pengaruh Model Pembelajaran Kooperatif

STAD Terhadap Hasil Belajar IPA pada Siswa Kelas V SD No.

5 Songan Tahun Pelajaran 2013/2014 Tersedia pada: http:

//ejournal.undiksha.ac.id/index.php /JJPGSD/article/view/5909.(diak ses tanggal 27 Februari 2017).

Trianto. 2007. Model-Model

Pembelajaran Inovatif

Berorientasi Konstrutivistik.

Jakarta: Perpustakaan Nasional. 